\title{
Ontogeny of actin and microsomal antigens in gastric parietal cells
}

\author{
R. CEREDIG ${ }^{1}$ AND B. H. TOH
}

From the Department of Pathology and Immunology, Monash University Medical School, Commercial Road, Prahran, Victoria 3181, Australia

SUMMARY Six fetal and 10 neonatal rat or mouse stomachs and a 14-week human fetal stomach were examined for immunofluorescence reactivity with four sera containing parietal cell antibody (PCA) and four other sera containing smooth muscle antibody (SMA). In rat and mouse stomachs, o parietal cells first reacted with PCA in 19-day fetal stomachs and with SMA in two-day neonatal $\infty$ rat stomachs or newly-born mouse stomachs. SMA reactivity with fetal rodent stomachs was 응 restricted to the cytoplasm of smooth muscle, the apices of gastric mucosal cells, and the cytoplasm of fibroblasts surrounding invaginating gastric pits. In the 14-week human fetal stomach, parietal cells $\subseteq$ stained with PCA but not with SMA. Specificity of the staining reactions was established by the $\overparen{\nabla}$ complete inhibition of PCA staining by serum absorption with a gastric microsomal fraction but $\vec{\varphi}$ not with actin. Conversely, the SMA staining was abolished by serum immunoabsorption with actin $\infty$ but not with the microsomal fraction. These observations, indicating that the development of the parietal cell microsomal antigen precedes that of actin, may be used to distinguish between the staining of parietal cells by SMA and PCA.

In a previous study (Ceredig and Toh, 1977), we reported that smooth muscle autoantibody (SMA) present in the sera of some patients with active chronic hepatitis (ACH) gave immunofluorescent staining of gastric parietal cells in a pattern indistinguishable from that obtained with parietal cell autoantibody (PCA). Furthermore, we also showed that this SMA reaction with parietal cells could be completely inhibited by serum absorption with skeletal muscle actin but not by a microsomal fraction derived from the gastric mucosa. Confirmation of the presence of actin in parietal cells has now been provided by the observation that experimentally produced anti-actin antibody reacts with these cells (Li et al., 1977). Also, ultrastructural studies using heavy meromyosin have shown that actin-like microfilaments are closely associated with the secretory canalicular system of parietal cells and that, during acid secretion, there is fusion of the membranes of the canalicular system and those of the apical tubulovesicular system (Vial and Garrido, 1976). Vial and Garrido (1976) suggested that actin filaments may play an active role in this intermembrane fusion.

1Present address: Walter and Eliza Hall Institute, Post Office, Royal Melbourne Hospital, Victoria 3050, Australia.

Received for publication 10 October 1977
Our demonstration of SMA reactivity with parietal $\stackrel{\mathbb{2}}{\Rightarrow}$ cells indicates that a confident diagnosis of PCA cannot be made on routine immunofluorescence tests using sections of adult stomach when SMA is also present in the same serum (Ceredig and Toh, 1977). The present study on the ontogeny of actin and microsomal antigens in gastric parietal cells was undertaken in an attempt to resolve this diagnostic problem.

\section{Material and methods}

PATIENTS`SERA

Four PCA and four SMA sera were used in this study. The four PCA sera, obtained from patients with pernicious anaemia, had staining titres of $\geqslant 32 \mathrm{~N}$ for adult mouse stomach. The PCA sera were also $\underset{\omega}{ }$ characterised by specific reactivity with parietal cells in stomachs derived from the adult rat, human, ox, $\infty$ rabbit, and guinea pig.

The four SMA sera obtained from patients with $\stackrel{?}{?}$ $\mathrm{ACH}$ were characterised by reactivity with smooth 0 muscle cytoplasm (Johnson et al., 1965), skeletal

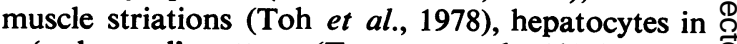

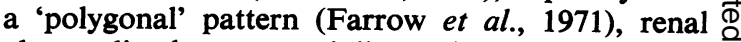
glomeruli, thymus medulla (Whittingham et al., 1966), parietal cells (Ceredig and Toh, 1977), and 
central nervous system synapses (Toh et al., 1976). The sera had staining titres of $\geqslant 64$ for smooth muscle, and $\geqslant 8$ for adult parietal cells (Ceredig and Toh, 1977).

All sera were used fresh or stored at $-30^{\circ} \mathrm{C}$ for up to three years when they were rapidly thawed in a $37^{\circ} \mathrm{C}$ water-bath and tested at an initial dilution of $1 / 8$.

\section{GASTRIC TISSUES}

Fetal and neonatal stomachs were obtained from pregnant Sprague-Dawley rats (weight $300 \mathrm{~g}$ ). Fetal rat stomachs were obtained from embryos at 14, 16, $18,19,20$, and 21 days of gestation. Neonatal rat stomachs were obtained from rats at $0,1,2,3,4,5$, $7,10,14$, and 21 days after birth. A parallel study using stomachs from fetal and neonatal BALB/c mice and a stomach from a 14-week human fetus was also carried out.

Specimens of the above tissues were snap-frozen in an isopentane-liquid nitrogen slurry at $-170^{\circ} \mathrm{C}$, and cryostat sections were examined for reactivity with SMA or PCA.

Comparable specimens of the above tissues were also fixed in $10 \%$ buffered formalin, and $6 \mu \mathrm{m}$ paraffin sections were stained with haematoxylin and eosin, Masson's trichrome, or a modified Zimmerman stain for parietal cells (Irvine, 1963).

\section{IMMUNOHISTOLOGY}

Cryostat sections of $6 \mu \mathrm{m}$ of fetal and neonatal stomachs were examined by indirect immunofluorescence (Nairn, 1976) with SMA or PCA. All stomachs were sectioned longitudinally so that representative areas of cardia, fundus, and antrum were present in the same section. The conjugate for immunofluorescent tracing of bound immunoglobulin was a fluorescein-isothiocyanate-labelled goat anti-human-gamma-globulin with a fluorescein to protein molar ratio of 4.0 and a protein content of $0.8 \mathrm{~g} / 100 \mathrm{ml}$. After immunofluorescent staining, the microscopical sections were examined by darkground ultraviolet fluorescent microscopy using a condenser fitted with a toric lens and a colourless barrier filter.

Specificity tests were carried out by immunoabsorption of SMA or PCA sera with skeletal muscle G-actin or a bovine microsomal fraction derived from the gastric mucosa (Ceredig and Toh, 1977).

\section{Results}

FETAL RAT STOMACHS

Primitive parietal cells, characterised by a slightly paler eosinophilic cytoplasm, were first seen as occasional cells at the bases of gastric pits of 19-day fetal rat stomachs. At this stage, the primitive gastric pits were seen as invaginations of the relatively undifferentiated epithelium into the deeper tissues; at the points of invagination these gastric pits were surrounded by a collar of fibroblastic cells (Fig. 1). The primitive parietal cells did not stain with the modified Zimmerman stain.

Cryostat sections of rat stomachs obtained from fetuses at 14,16, and 18 days of gestation gave negative staining reactions with PCA. However, in 19-day fetal rat stomachs, weak cytoplasmic staining of primitive parietal cells by PCA was seen (Fig. 2).

Parallel cryostat sections of fetal rat stomachs reacted with SMA gave staining of the smooth muscle of the muscularis externa, the apices of occasional gastric mucosal cells, and the cytoplasm of fibroblasts surrounding invaginated gastric pits (Fig. 3). The cytoplasm of mucosal cells, including those of primitive parietal cells, did not stain.

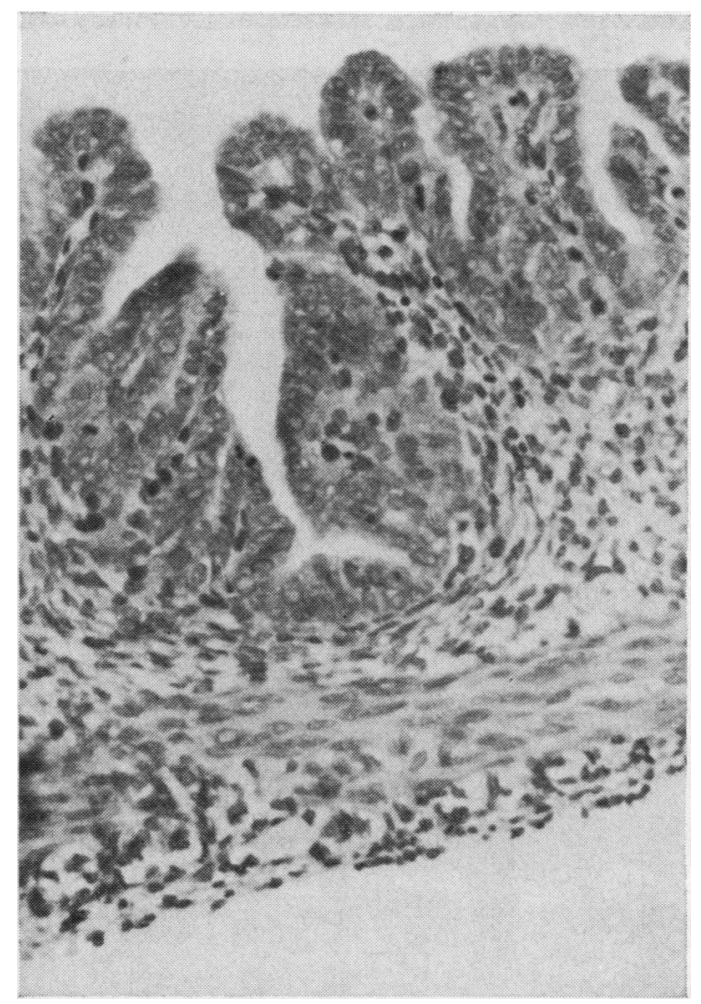

Fig. 1 Nineteen-day fetal rat stomach showing invagination of relatively undifferentiated mucosal epithelium into the deeper tissues. A collar of fibroblastic cells surrounds the margins of the invaginated gastric pits. Haematoxylin and eosin $\times 250$. 


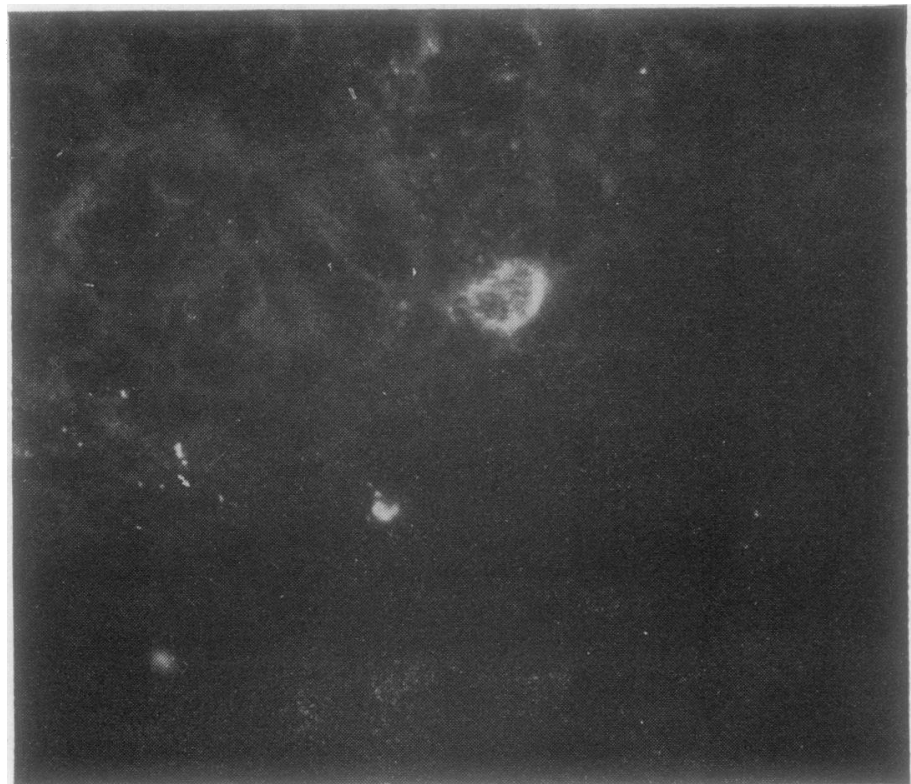

Fig. 2 Nineteen-day fetal rat stomach, reacted with $P C A$, showing cytoplasmic staining of a primitive parietal cell. Indirect immunofluorescence $\times 500$.

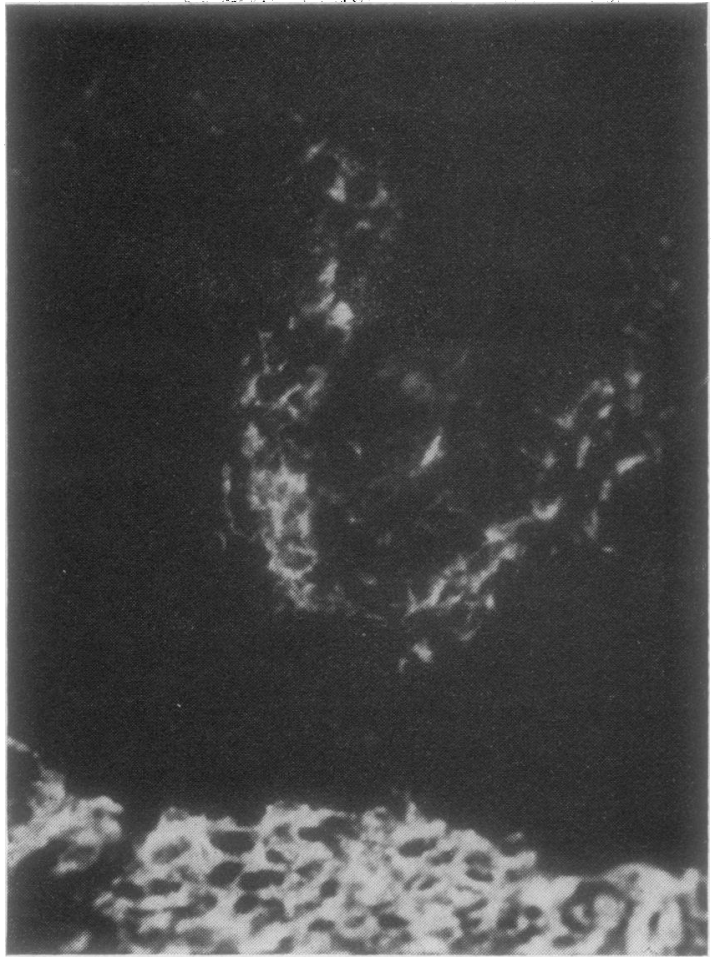

Fig. 3 Similar field to that in Fig. 1, reacted with $S M A$, showing staining of the muscularis externa, the apices of gastric mucosal cells, and the cytoplasm of fibroblasts surrounding invaginated gastric pits. Indirect immunofluorescence $\times 200$.
RAT STOMACHS AT BIRTH

At birth, the mucosa had developed and differentiated considerably with an increase in number and size of gastric glands; parietal cells with an eccentric nucleus and pale eosinophilic cytoplasm were clearly seen (Fig. 4). A distinct muscularis mucosae, comprising several cell layers, was also present. The parietal cells reacted positively with the modified Zimmerman stain.

Cryostat sections of these stomachs gave granular cytoplasmic fluorescence of parietal cells when reacted with PCA (Fig. 5). The cytoplasm of these cells did not react with SMA; positive SMA staining was restricted to the apices of mucosal cells, the muscularis mucosae (Fig. 6), and the muscularis externa.

\section{NEONATAL RAT STOMACHS}

Further maturation of the gastric mucosa occurred in the first week after birth. At 6 days after birth (Fig. 7) the glands had increased in depth, the gastric pits were lined by predominantly mucus-producing cells, the mucosa was considerably folded with rugae formation, the muscularis mucosae projected as villous cores between gastric glands, and clearly identifiable parietal cells were presented; the latter reacted positively with the modified Zimmerman stain.

In cryostat sections of 2-day-old neonatal rat stomachs, occasional parietal cells gave weak staining with SMA. In 6-day-old stomachs, parietal cells reacted with PCA (Fig. 8) and SMA (Fig. 9) in patterns identical with those seen in adult rat 


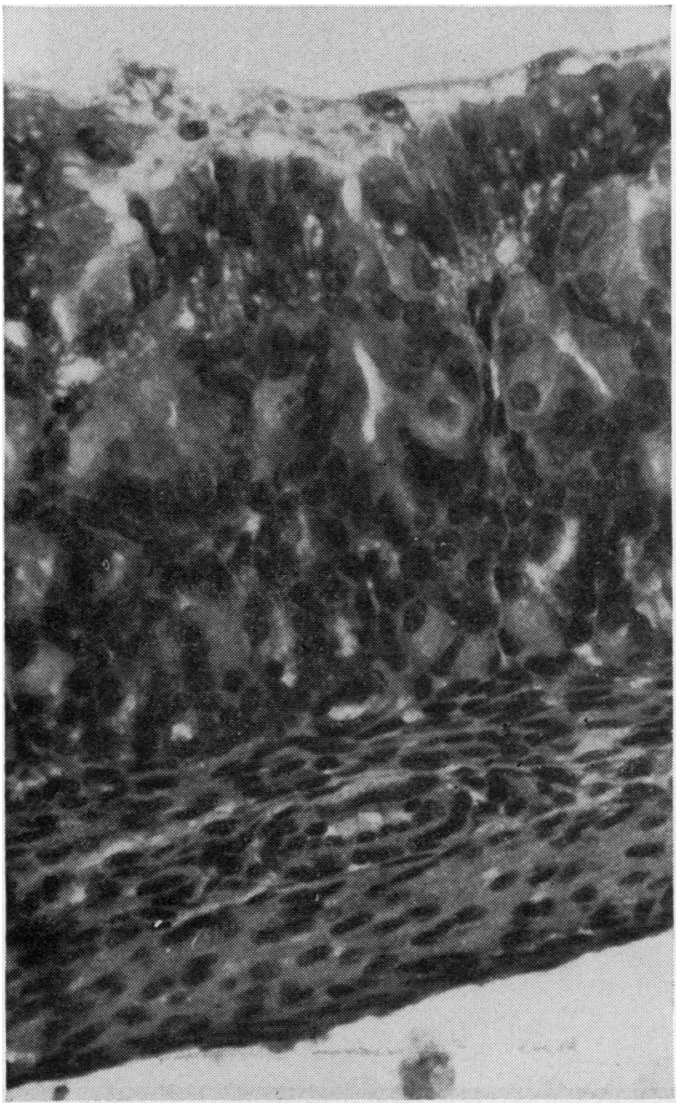

Fig. 4 Rat stomach at birth showing numerous gastric glands. Parietal cells with an eccentric nucleus and pale cytoplasm are clearly seen. $H \& E \times 320$.

stomachs. The intensity of SMA staining of parietal cells was greater in those parietal cells at the bases than in those at the neck of glands.

FETAL AND/OR NEONATAL MOUSE AND HUMAN STOMACHS

A similar study carried out on fetal and neonatal mouse stomach showed that the earliest reaction of parietal cells with PCA was seen in stomachs from 19-day-old fetuses while that with SMA was first seen in stomachs from newly born mice ( 22 days).

Cryostat sections of human stomach obtained from a 14-week fetus showed that parietal cells stained with PCA (Fig. 10) but not with SMA; the latter autoantibody reacted only with smooth muscle (Fig. 11).

\section{SERUM TITRATIONS}

The results of titrations of one PCA (76/2776) and one SMA (74/2001) serum against sections of fetal

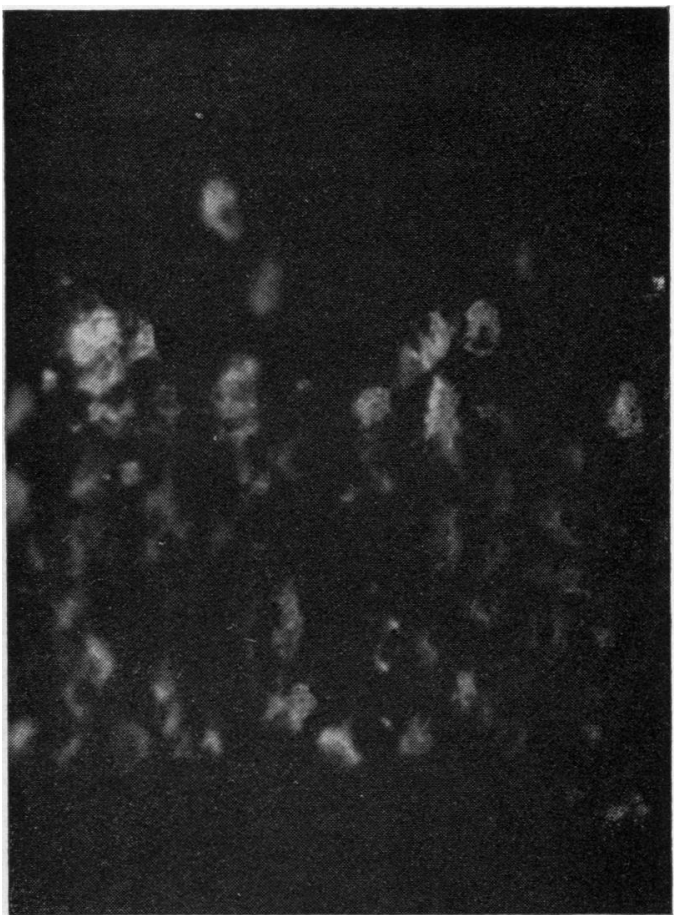

Fig. 5 Similar field to that in Fig. 4, reacted with PC.A, showing granular cytoplasmic fluorescence of parietal cells. Indirect immunofluorescence $\times 200$.

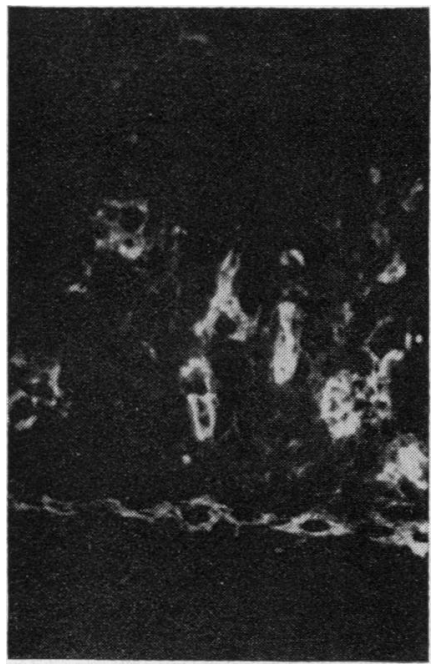

Fig. 6 Similar field to that in Fig. 4, reacted with $S M A$, showing staining of the apices of mucosal cells and the muscularis mucosae. Indirect immunofluorescence $\times 200$. 


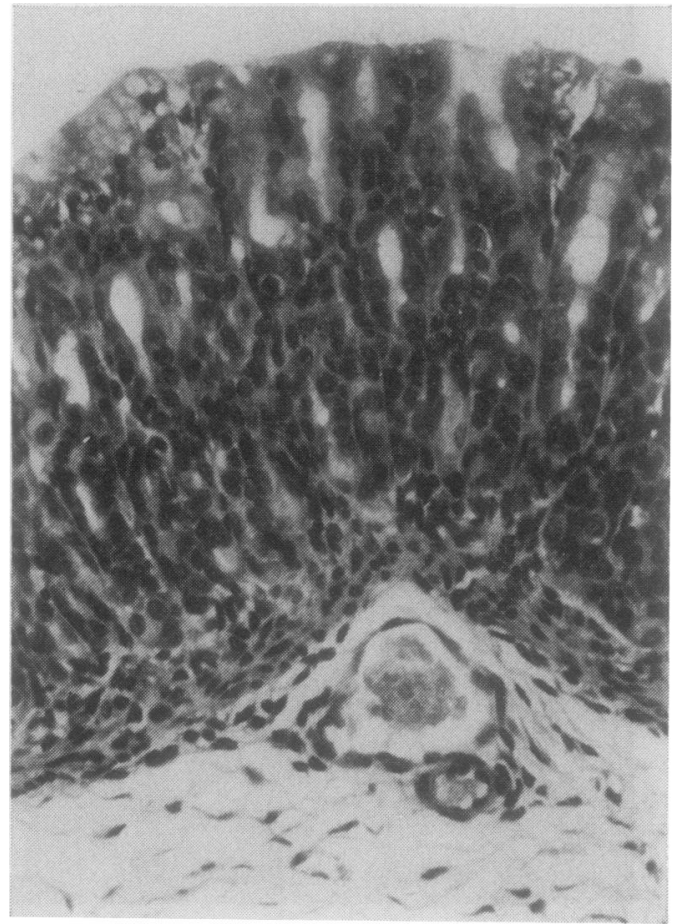

Fig. 7 Six-day neonatal rat stomach, showing deep gastric pits lined predominantly by mucus-producing cells. Clearly identifiable parietal cells are present. $H \& E \times 250$.

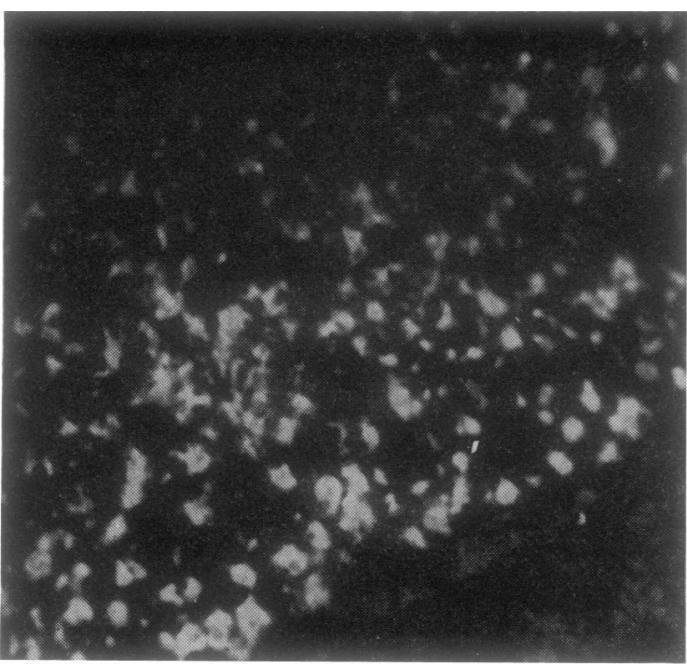

Fig. 8 Similar field to that in Fig. 7, reacted with PCA, showing staining of the cytoplasm of parietal cells. Indirect immunofluorescence $\times 200$.

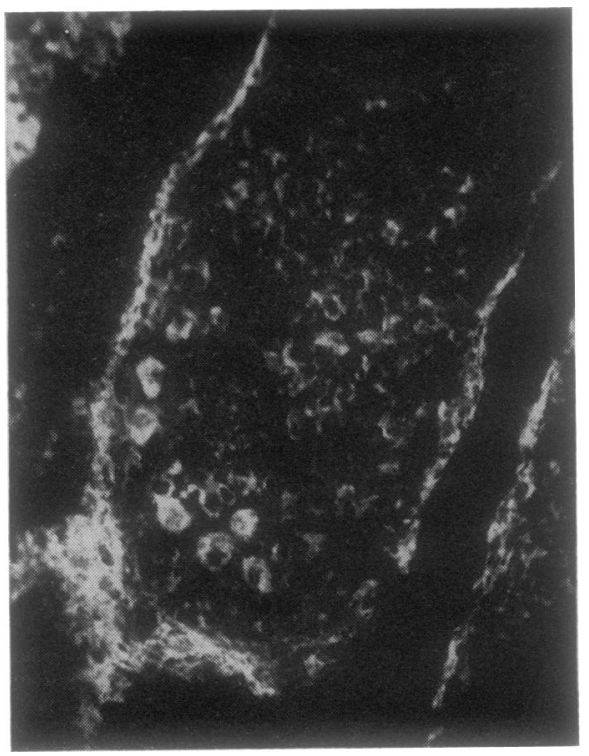

Fig. 9 Similar field to that in Fig. 7, reacted with $S M A$, showing staining of the muscularis mucosae and the cytoplasm of parietal cells. Indirect immunofluorescence $\times 200$.

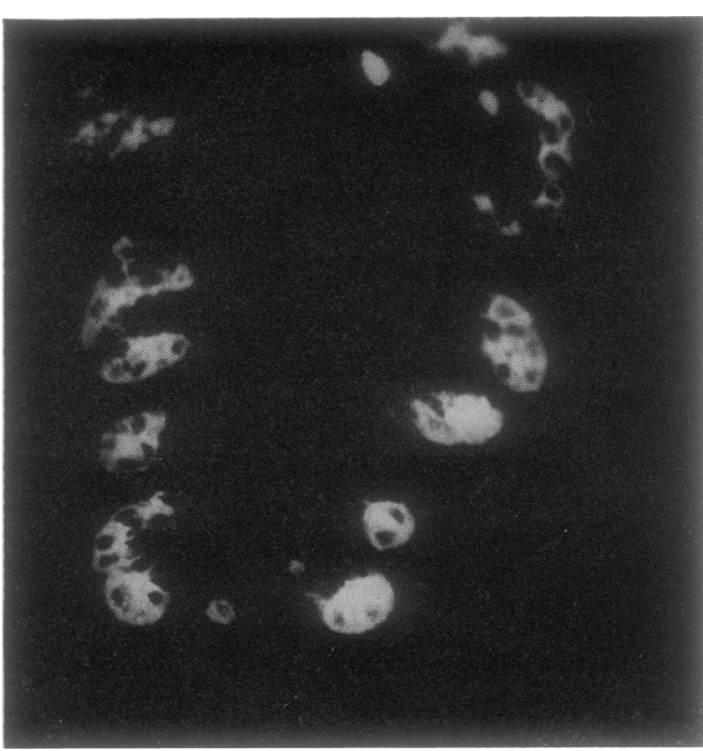

Fig. 10 Fourteen-week human fetal stomach, reacted with PCA, showing staining of parietal cells. (The muscularis did not stain.) Indirect immunofluorescence $\times 320$. 


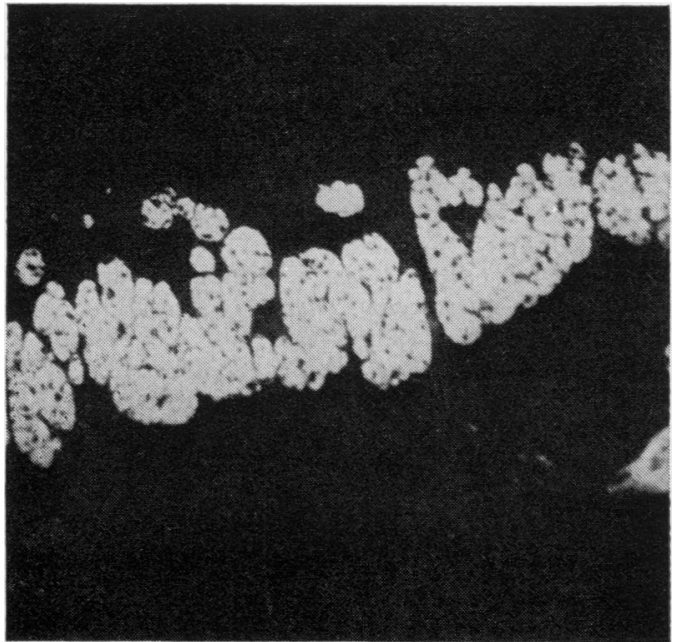

Fig. 11 Similar field to that in Fig. 10, reacted with SMA, showing staining of the muscularis externa. Parietal cells do not stain. Indirect immunofluorescence $\times 320$.

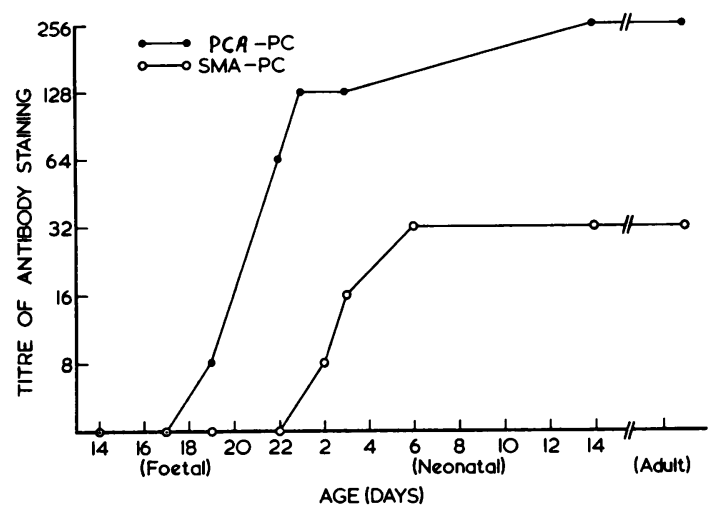

Fig. 12 Results of titrations of PCA and SM.A against rat parietal cells $(P C)$.

and neonatal rat stomachs are shown in Figure 12. The PCA serum, with a staining titre of 256 for adult rat parietal cells, gave a titre of 8 for parietal cells in stomachs from 19-day-old fetuses; adult titres were attained 14 days after birth. The SMA serum, with a titre of 256 for fetal and adult smooth muscle and 32 for adult parietal cells, gave a titre of 8 for parietal cells in 2-day-old neonatal rat stomachs; adult titres were obtained with 6-day-old neonatal stomachs.

\section{SPECIFICITY STUDIES}

Immunoabsorption experiments showed that the staining of parietal cells by PCA was completely inhibited by serum absorption with a gastric microsomal fraction from bovine stomach but not by skeletal muscle G-actin. Conversely, the staining of parietal cells by SMA was completely inhibited by serum absorption with G-actin but not by the gastric microsomal fraction.

\section{Discussion}

The results of our studies indicate that the development of gastric parietal cell (microsomal) autoantigen and that of parietal cell actin are completely dissociated in the rat, mouse, and human stomachs. In all three species, the development of the gastric microsomal antigen preceded that of actin.

The demonstration of the gastric microsomal antigen by PCA in rat gastric parietal cells at 19 days of gestation correlates well with light and electron microscopic identification of parietal cells at this stage of development (Helander, 1969). Also, Hoedemaeker and Ito (1970), using the immunoperoxidase labelling technique, have ultrastructurally localised PCA staining to the membranes of the secretory canalicular system; and this membrane system is well developed in 19-day fetal rat stomachs (Helander, 1969). Furthermore, although lack of material prevented a complete developmental study in the human, demonstration of the parietal cell autoantigen in the 14-week fetal human stomach is consistent with the report that identifiable parietal cells have already developed at 11 weeks of gestation (Nomura, 1966). The results suggest that PCA may be used as a marker for morphologically developed parietal cells.

Previous studies have reported that morphological maturation of parietal cells occurs before functional maturation (Helander, 1969). For instance, whereas parietal cells are morphologically identifiable by day 19 of gestation in the mouse, acid secretion does not occur until four days after birth (Deren, 1971). Also, in the human, while parietal cells are first identified histologically at 11 weeks' gestation, acid secretion begins only at 16 weeks (Nomura, 1966). We and others (Vial and Garrido, 1976) have postulated that actin-like microfilaments in parietal cells may play a role in acid secretion. Our demonstration that the development of actin in parietal cells occurs after that of the microsomal antigen but before the onset of acid secretion is consistent with this view.

The luminal staining of gastric mucosal cells by SMA may represent actin-like microfilaments. The latter have been identified ultrastructurally in similar apical locations in other developing glands (Wessells et al., 1977). Wessells et al. (1977) have suggested that gland formation by invagination of mucosal epithelium may occur as a result of contraction of 
microfilament 'purse-strings'. We suggest that the presence of actin in these apical sites in mucosal cells may play a similar role in gastric gland formation. This suggestion is supported by the demonstration that cytochalasin B, which reversibly disrupts microfilaments, specifically inhibits corticosteroid-induced rat gastric mucosal maturation and differentiation (Yeomans et al., 1976).

The fibroblasts surrounding gastric pits may represent a mesenchymal reaction to the invaginating gland. These cells stained positively with SMA. They probably correspond to 'myofibroblasts' previously described in healing wounds (Gabbiani et al., 1972). Similar myofibroblastic reaction to invading tumours has also been reported (Toh et al., 1977).

Finally, the demonstration that the expression of actin and of microsomal antigens are dissociated in the developing stomach provides a means of distinguishing parietal cell staining by PCA and SMA. We recommend that, in clinical situations where there is staining of both smooth muscle as well as parietal cells, sections of stomachs of new-born rats should be tested with the serum to determine whether there are one or two autoantibodies present.

We thank Miss Vivien Randell for technical assistance, Dr H. A. Ward for the gastric microsomal fraction, and Dr F. M. Clarke for the skeletal muscle G-actin. This work was supported by grants from the Anti-Cancer Council and the National Health and Medical Research Council of Australia.

\section{References}

Ceredig, R., and Toh, B. H. (1977). Reaction of human smooth muscle autoantibody with gastric parietal cells: a pitfall in the diagnosis of parietal cell autoantibody. Journal of Clinical Pathology, 30, 666-670.

Deren, J. S. (1971). Development of structure and function in the fetal and newborn stomach. American Journal of Clinical Nutrition, 24, 144-159.

Farrow, L. J., Holborow, E. J., and Brighton, W. D. (1971). Reaction of human smooth muscle antibody with liver cells. Nature, New Biology, 232, 186-187.

Gabbiani, G., Hirschel, B. J., Ryan, G. B., Statkov, P. R., and Majno, G. (1972). Granulation tissue as a contractile organ. A study of structure and function.
Journal of Experimental Medicine, 135, 719-734.

Helander, H. F. (1969). Ultrastructure and function of gastric parietal cells in the rat during development. Gastroenterology, 56, 35-52.

Hoedemaeker, P. J., and Ito, S. (1970). Ultrastructural localization of gastric parietal cell antigen with peroxidase-coupled antibody. Laboratory Investigation, 22, 184-188.

Irvine, W. J. (1963). Gastric antibodies studied by fluorescence microscopy. Quarterly Journal of Experimental Physiology, 48, 427-438.

Johnson, G. D., Holborow, E. J., and Glynn, L. E. (1965). Antibody to smooth muscle in patients with liver disease. Lancet, 2, 878-879.

Li, A. K. C., Trenchev, P. S., Holborow, E. J., Newsome, C., and Wynne, A. T. (1977). Experimental smooth muscle antibodies. Clinical and Experimental Immuno$\log y, 27,273-277$.

Nairn, R. C. (1976). Fluorescent Protein Tracing, 4th edition, Churchill Livingstone, Edinburgh and London. 음

Nomura, Y. (1966). On the submicroscopic morpho- genesis of parietal cell in the gastric gland of the human foetus. Zeitschrift für Anatomie und Entwicklungsgeschichte, 125, 316-356.

Toh, B. H., Cauchi, M. N., Cook, P. C., and Muller, $\vec{\theta}$ H. K. (1977). Increased expression of actin-like $\infty$ contractile protein in preneoplastic and neoplastic $\square$ lesions in rat liver. British Journal of Cancer, 35, 761-767.

Toh, B. H., Clarke, F. M., and Ceredig, R. (1978), Reaction of human smooth muscle autoantibody with $\stackrel{\circ}{\circ}$ skeletal muscle, cardiac muscle and thymic nyoid cells. Clinical Immunology and Immunopathology, 9, 28-36.

Toh, B. H., Gallichio, H. A., Jeffrey, P. L., Livett, B. G., Muller, H. K., Cauchi, M. N., and Clarke, F. M. (1976). Anti-actin stains synapses. Nature, 264, 648-650.

Vial, J. D., and Garrido, J. (1976). Actin-like filaments and membrane rearrangements in oxyntic cells. Proceedings of the National Academy of Sciences of the United States of America, 73, 4032-4036.

Wessells, N. K., Spooner, B. S., Ash, J. F., Bradley, M. O., Luduena, M. A., Taylor, E. L., Wrenn, J. T., and Yamada, K. M. (1977). Microfilaments in cellular and developmental processes. Science, 171, 135-143.

Whittingham, S., Mackay, I. R., and Irwin, J. (1966). D Autoimmune hepatitis: immunofluorescence reactions with cytoplasm of smooth muscle and renal glomerular $\overline{\mathrm{N}}$ cells. Lancet, 1, 1333-1335.

Yeomans, N. D., Trier, J. S., Moxey, P. C., and Markezin, N E. T. (1976). Maturation and differentiation of cultured $N$ fetal stomach. Gastroenterology, 71, 770-777. 